\title{
FRONT-END DESIGN AND VALUE GENERATION: A HOUSING PROJECT ANALYSIS
}

\author{
Joas Serugga ${ }^{1}$, Bernardo Martim Beck da Silva Etges ${ }^{2}$, \\ Ellen Bernardi ${ }^{3}$, and Mike Kagioglou ${ }^{4}$
}

\begin{abstract}
There is an increasing interest in the role of Front-end Design (FED) as one of the vital stages of design processes. It is the stage in which project purposes and goals are defined, requirements captured, refined, and managed and trade-offs are made considering each consequence. It is also the stage where project requirements are transformed into design requirements for implementation by professional teams. FED sets the earliest opportunities for project collaboration to facilitate value generation and delivery. Decision making in this stage often affects most of the later processes in a project. Yet, little evidence and literature exist to support FED design process. This paper examines the role of FED in housing projects, and more specifically investigating one contemporary housing development case study in Porto Alegre-Brazil, exploring how FED facilitated value generation. The research found some evidence of value management in FED processes in the case study. It is also found that more research into user requirements capture and how these facilitate value generation is still required. This paper adds to the growing body of literature in this vital area stage of the design process.
\end{abstract}

\section{KEYWORDS}

Design, Front-End Design, Value, Trust and Collaboration

\section{INTRODUCTION}

Since Koskela's (1992) seminal work into construction as a production process, there has been an emergent new understanding of value creation in the Architectural, Engineering, and Construction (AEC) industry. Part of this emergent understanding has focused on the vital role for the FED in contributing to overall project performance. The critical link between FED and value generation can be found in how it facilitates participatory design through collaborative requirements capture and understanding of user requirements (Gomes et al. 2016) and value co-creation (Giménez et al. 2019). The sector's approach

1 PhD Researcher, University of Huddersfield, UK, joas.serugga@hud.ac.uk, orcid.org/0000-00025814-1522

2 PhD Candidate, Universidade Federal do Rio Grande do Sul, Partner at Climb Consulting Group, Brazil. bernardo.m.etges@gmal.com, orcid.org/0000-0002-3037-5597

3 Master Student, Universidade Federal do Rio Grande do Sul, Partner at OSA, Brazil, ellen@ospa.com.br, orcid.org/0000-0001-9125-0344

4 Dean of School of Engineering, Western Sydney University, Australia, M.kagioglou@westernsydney.edu.au, orcid.org/0000-0003-3521-1484 
to value generation is still largely traditional and limited collaborative practices are evident during design (Salam et al. 2019).

The latter is partially due to the limited research and understanding of the role of design as a key driver in value generation (Serugga et al. 2019). Kagioglou and Tzortzopoulos (2016) and Salam et al. (2019) highlight that decision making and the intensive information exchanges in multi stakeholder FED, coupled with the dynamic and iterative nature of FED, can be challenging. Integration and collaboration are important in establishing a structured design process. A structured process is essential to mitigating waste which is endemic within AEC (Mota et al. 2019; Tezel et al. 2018). It ultimately leads to delayed, overpriced and poor quality project delivery (Polat and Ballard 2004) though appreciably, Smyth et al. (2018) argue that value extends beyond the traditional constraints of scope, time and cost.

FED as a specific and essential stage of the Design processes anchors many preceding processes (Gomes et al. 2016; Samset and Volden 2016). Almqvist (2017), highlighted gaps between expected and achieved value arising in part out of an unstructured FED process. FED involves such activities as ideation, business case definition, project case definition and other stages all of which do contribute and anchor later stages in design (Lawson 2005; Whelton and Ballard 2002). Decision making in FED does set the impact on the flow of processes in the value generation as well as representing a key stage in collaborative value creation (Pikas et al. 2019).

There has been an emergence of various research and models to supporting collaborative value co-creation (Smyth et al. 2018). The use of Building Information Modelling (BIM) by many AEC practices is one such advent in supporting the management of AEC processes (Sacks et al. 2009) and improving communication between stakeholders (Azhar 2011; Fürstenberg and Lædre 2019). Azhar (2011) reports that the use of virtual modelling environments has improved building information exchanges in process areas such as planning, design, construction, and operation of the facility. Von Heyl and Demir (2019) are among a growing number of authors highlighting the challenges of adoption of such tools in practice not least the extra risks relating to context specific understanding. In Brazil for example, although there are some demonstrable cases of how user requirements are managed through BIM, there still remains some structural problems within the AEC sector impeding progress as compared other countries such as UK, USA or even Egypt, where BIM is already a reality in regulatory environments (Dainty et al. 2017). FED, can represent the whole product development process that precedes the detail design (Samset and Volden 2016; Serugga et al. 2020; Whelton and Ballard 2002). FED processes, therefore, integrate stakeholders' needs in supporting value generation, alongside definition of project scope, costs, and risks among other design decision-making processes. Against this backdrop, the present paper investigates, through a Case Study from the city of Porto Alegre, Brazil how the FED factors influenced design decision making in the development of a housing project.

The paper is divided, firstly, in the review of the literature about FED followed by the research method. The following section explores how the various elements of FED impact on design decision making in the case study. The conclusions follow together with suggested improvements and identifications of any opportunities for applying FED in future projects to value delivery in FED. 


\section{FRONT-END DESIGN}

Throughout literature, FED is observed of consisting of various stages and configurations (Figure 1) though these can be summarized more generally from such authors as Whelton and Ballard (2002) and Lawson (2005) as: project mission, scope and purpose definition, feasibility and justification, outline designs and costs/benefits analysis, project funding, project risk management, general and outline execution plan. In determining the project mission and the need, the project processes harness a wide variety of information and knowledge from among its stakeholders. This is, for example, to justify why a project would be needed as well as having clarity of its intended benefits. The need case could be a business objective such as determining or prospecting for a project that the stakeholders believe, based on information available to them, will have appeal and use need. The next stage is to determine the project scope. This could be through a feasibility study where basic parameters can be scoped out into a formal proposal for the project to set the basis for downstream processes. This is the time the project team should be thinking and considering the high project purpose and any high-level goals. Turner and Cochrane (1993) have argued that many of the project goals and methods might not be known at the start, something that inherently contributes to many project complexities particularly in during FED in dynamic contexts. Baccarini (1996) later argues that perhaps this lends to the limited knowledge about project complexity in current literature and practice. Yet, Williams (1999) has observed that a lot of project complexity in downstream processes stems from poorly defined goals and methods. According to San Cristóbal (2017) given the need to facilitate planning, modelling, controlling and evaluation of the project processes, it is essential that the project engages widely so as to have as much information as possible to draw on in any decisions taken as to the purpose and goals (Turner and Cochrane 1993). Only then should the development of outline design start.

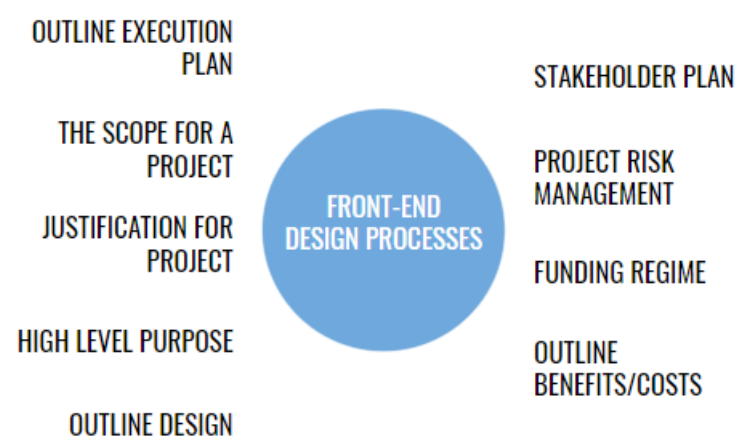

Figure 1: Dimensions considered in the Front-end design process

(Developed by the authors)

Lawson (2005) argues that a lot of information does emerge down the line in the development process. Outline schemes and any imagery have to be considered as simply part of that evolving process of value generation, he argues. In considering the value for the project, user requirements to be transformed into design requirements have to be harnessed in a collaborative environment (Gomes et al. 2016) to support value co-creation (Smyth et al. 2018). Understanding user needs in a project is important in any proceeding processes such as in any subsequent cost-benefit analysis or trade-offs. The risk 
management processes aim to identify, define, manage or mitigate project risks (Adeleke et al. 2017). The authors highlight that the more risks that are outsourced, potentially, the higher the project costs might be. As the outline designs take on more detail, so do the risks associated with that particular part of the project detail. Additionally, the progressive detailing of the designs informs the needs and requirements of the project, stakeholders and organization.

With the project's mission, scope, purpose, goals, designs, stakeholder arrangement, among other aspects defined, a project execution plan has to be put in place to espouse all these elements. Based on this FED conceptualization, it is conceivable that a successful FED process requires a collaborative environment grounded in an understanding of project objectives. Supporting these processes is essential such as in stakeholder management during information and knowledge exchanges that inform decision making - essentially increasing the evidence base guiding design decision making

\section{METHOD}

The objective of this paper is to verify the role of FED decision making within the design and development of a real estate housing project.

For this objective, the research seeks: (a) to develop the literature review about the subject (b) understand how the case study fits into the development dimensions of the project that makes up the FED (c) suggest improvement opportunities for future projects that aim to maximize the value to the end-user.

A case study approach is, therefore, adopted to understanding the intricate dynamics of FED in contributing to value delivery in a housing context in Porto Alegre, Brazil. For this specific design project, the research team directed a detailed analysis following open interviews with designers and mains contractors in two Companies involved in the FED development of a Housing Project.

\section{STAKEHOLDER DESCRIPTION}

A multi-level residential building is the subject of research and analysis of this paper involving many stakeholders. Table 1 summarizes the roles of the various stakeholders in the project implementation processes. The range of stakeholders at the organizational level in this project delivery involved a Real Estate Developer and Construction (Company 01) as lead, and a Design and Engineering practice (Company 01) Both companies are based in Porto Alegre, Brazil. Other stakeholders had to link in with those main actors.

\section{COMPANY 01 - REAL ESTATE DEVELOPER AND CONSTRUCTION RESPONSIBLE}

The company, founded in 2014, has been gaining traction in the city's construction sector owing to its team wide experience in the sector gained over the years throughout many challenging projects. The company recently has been responsible for the delivery of several high-end housing with a focus on user benefits as part of its core offering. 
Table 1: Companies $01 \& 02$ - Actors and Roles

\begin{tabular}{|c|c|c|c|c|c|c|c|c|c|c|}
\hline & 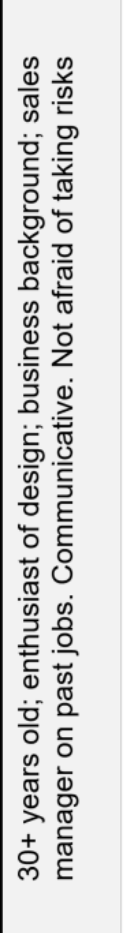 & 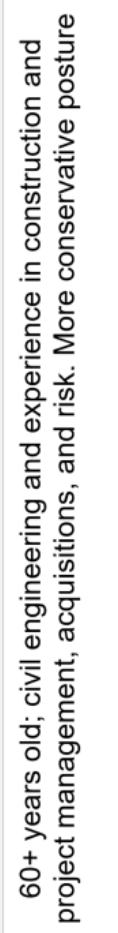 & 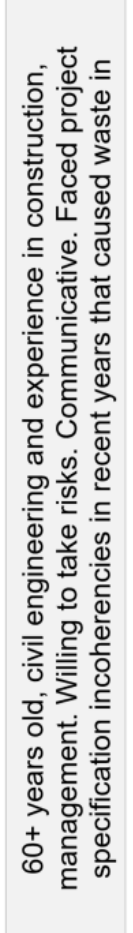 & 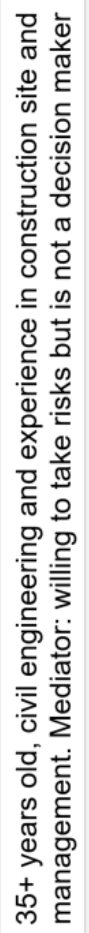 & 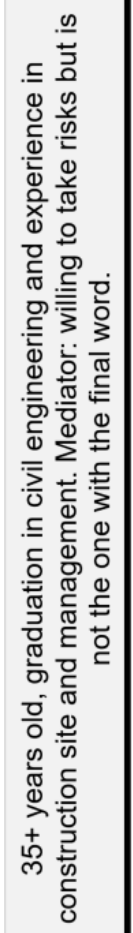 & 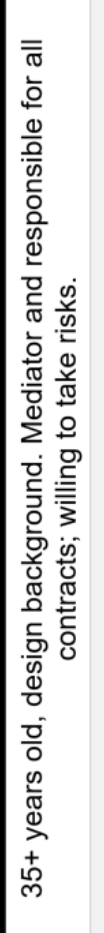 & 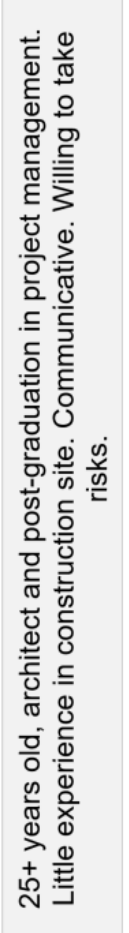 & 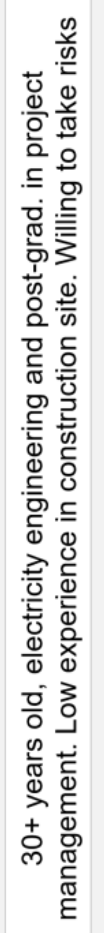 & 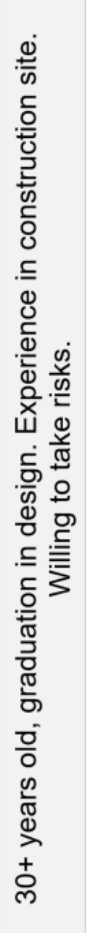 & 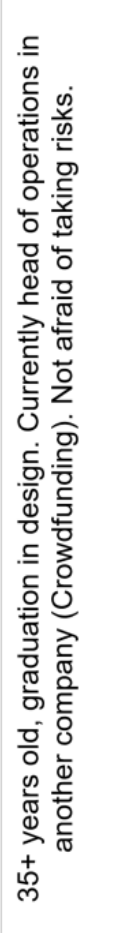 \\
\hline & 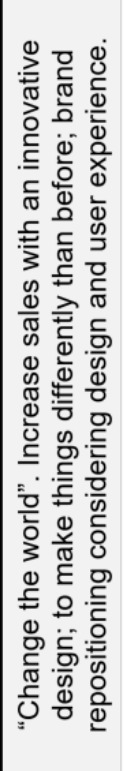 & 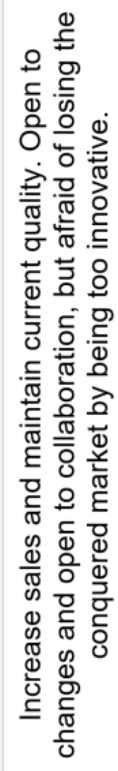 & 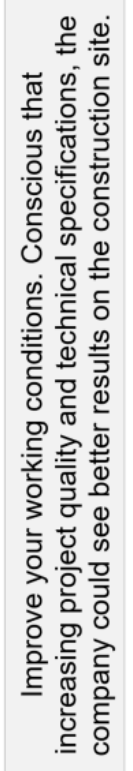 & 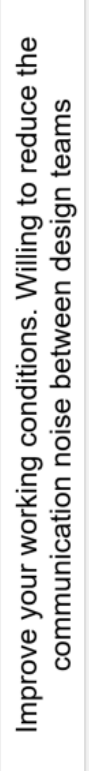 & 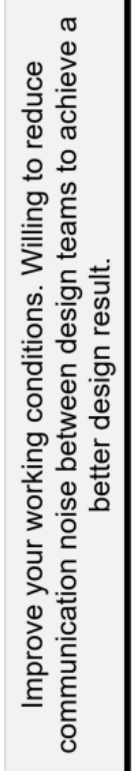 & 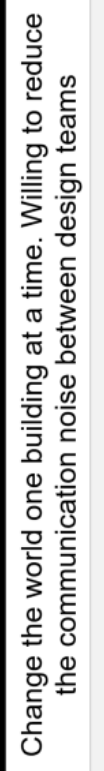 & 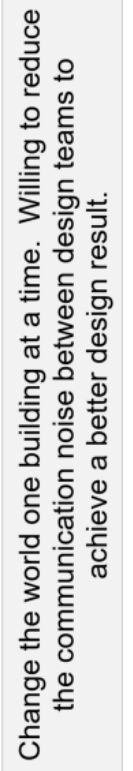 & 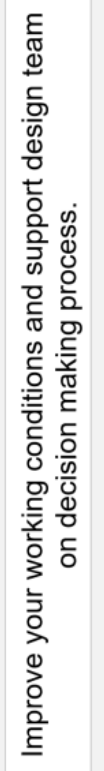 & 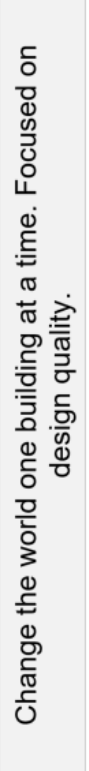 & 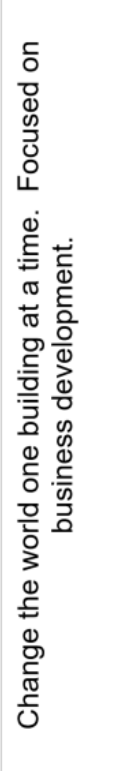 \\
\hline$\overline{0}$ & 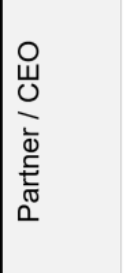 & 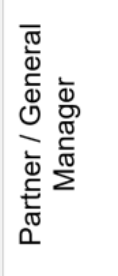 & 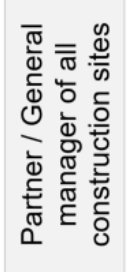 & 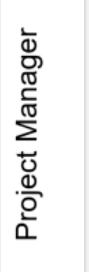 & 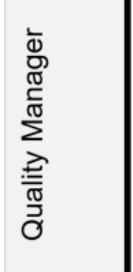 & 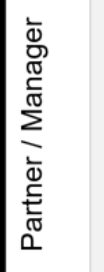 & 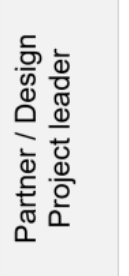 & 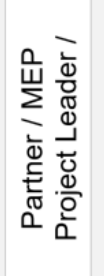 & 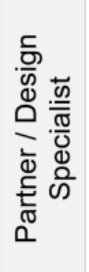 & 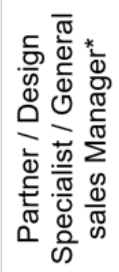 \\
\hline 2 & $\overline{\dot{j}}$ & $\frac{N}{\dot{v}}$ & $\frac{m}{\dot{j}}$ & $\dot{0}$ & $\dot{0}$ & & ָ̃ & 0 & ชิ & 0 \\
\hline & \multicolumn{5}{|c|}{ Lo Kueduo } & \multicolumn{5}{|c|}{ zo Kueduo } \\
\hline
\end{tabular}


The company acts as a management and developer stakeholder, helping identify potential sites and carrying out pre-construction processes including liaising with designers, compliance, building control, planning teams, contractors, and funders, among others. The company sees itself as innovative and collaborative in its approach to housing development. During the process of data collection, collaborative processes were observed in areas such as strategy development for end-user engagement in the process of project delivery, particularly in FED processes. Engagement is through workshops and events to support requirements management across a range of stakeholder profiles, including end-users and experts.

This process of value co-creation through a proactive understanding of user requirements has been adopted for five of their recent residential projects. Collaborative processes with the developer extend to developing strong links with sectoral stakeholders in embedding a process of collaborative and shared organizational learning and knowledge sharing. For example, many of the company's design processes are with the same design and engineering teams. The process of long-term relationships with stakeholders such as these ensures the company can leverage previous knowledge to inform decision making in new projects in a collaborative manner. However, the project that is the subject of this paper with a one-year lead time was developed by a new contractor team. This meant new demands both from a contractual arrangement and new forms of knowledge and information sharing forums with existing stakeholders such as designers and engineering teams. FED processes, therefore, came under new influences and constraints as a result.

\section{COMPANY 02 - DESIGN AND ENGINEERING PRACTICE}

The Company 02 evolved from an interior design background in 2003 in Porto Alegre, Brazil. Over the years, the practice has gained wide experience and understanding of the intricate nature of design needs and trends in the city that are critical to the successful delivery of housing projects. This owes in part to the company's growing links with major stakeholders in the city such as planning and control, contractors, evolving user needs, among others. The company now offers integrated design, engineering, legal and compliance, finance and accounting, economic planning, and construction project management services among others. The unique set of skills has allowed the company to innovate in such areas as the inaugural fully-fledged housing development crowdfunding service that has gained the sector-wide appeal among property developers in the city seeking innovative solutions. Other innovations reinforcing the company's approach to collaboration and innovation also include its full adoption of Building Information Modelling (BIM) that contributes further to its drive for transparency and information and knowledge sharing in its processes. Dynamism is also an essential element in the company's practices in ensuring responsiveness to changing market needs, such as following the country's housing downturn over the last decade.

\section{The Housing Project}

The project is the first of in a wider scheme of current projects executed by Company 01 in conjunction with Company 02. The building has a silhouette focusing on the need for expanded living spaces. The cascading typology grants the best site exploitation and maximizes the private area of units using private terraces. The base of the building shelters the common areas (party room, gym and lobby) as well as the parking lot. 


\section{THE DESIGN PROCESS - FINDINGS}

Company 01 after conceptualizing the project and following an initial feasibility study liaised with Company 02 in February 2017 to evaluate the benefits of using BIM in supporting the delivery of projects. The collaborative process informed the definition of the project scope and working methods, culminating in a decision to develop a multiple residence building.

The project process began officially in May 2017 with an initial meeting with the design team of Company 02 and the core of Company 01 - two experienced engineers in construction management, the project manager, and the CEO. It was observed that this process did not require the presence of engineering teams from Company 2 as it was a preliminary analysis of the legal and numerical conditions of the site.

It was also observed that these initial engagements lacked structure in collating user requirements as interpreted by the design team. Company 01 considered that they had sufficient information regarding the land, the neighbourhood, and the potential users in this specific project to provide to designers to develop the initial phase of the design. The briefing process also summarized as below:

- The Company 01 relied on information from previous engagement workshops for projects of similar user and design characteristics. The Workshop aimed to understand user requirements through collaboration with potential and existing users, design students and through expert interviews to inform the requirements management process. The workshops adopted a proactive and planned approach to maintain rigour in the process and its results. The main drivers for user requirements and use benefits at the time of the briefing were identified as ample spaces in the shared spaces of the apartments, functional layout, adaptability of the living space including to internal organization of furniture. Other requirements included contemporary functional design form such as in the application of glazing to maximize views while at the same time maximizing energy performance regarding solar loss/gain. Also crucial in the identified requirements was the possibility for more shared spaces - such as laundry, party rooms and gyms within the development. On the other hand, experts and design enthusiasts were more related to requirements including integrated designs, physical site management and designs integrated into the community and landscapes.

- Requirements as understood from Company 01 perspective, were related to economic performance, strategic value, and constructions costs. From the company's perspective, project benefits related more to how the design contemplated the largest possible scope and use mix of the apartments to meet the diverse target end-users' current and emergent needs. The smaller apartments would, for example, be targeted to investor buyers, which would guarantee greater liquidity of the business. The larger apartments would in the company's view be targeted to young families. This all suggests bias towards economic performance in their view.

- Technical and related health and safety requirements were also considered such that based on then market prices, ideal space requirements ranged from $40 \mathrm{Sqm}-65 \mathrm{Sqm}$ for a competitive value proposition in the market. This estimate was also informed by Company 01 's previous developments within the immediate locality.

- Other technical requirements involved consideration for the project lead time that were constrained by the project's funding structure. It was expected that the use of such capabilities as BIM would support this endeavour in processes through 
collaboration and efficient information and knowledge sharing among teams, particularly in the implementation stages.

- Project governance requirements were also considered in this process relating to stakeholder management and understanding of the project context. Previous work in the immediate locality provided good teams' knowledge about constraints such as relating to the foundations and underground works and the corresponding mitigations.

The project requirements were, therefore, influenced by the understanding of the contextual dynamics that informed the FED processes. Other requirements relating to symbolism were also seen to subtly influence design decision making, such as in Company 01's insistence on an iconic design that is distinct in the region where the project is located.

\section{DISCUSSION}

\section{CONCEPT EVALUATION}

Six review stages in the conceptual phase of the project - and almost three months - were necessary for the designers to meet the project objectives as defined in the briefing stage.

Given the number of constraints, the concepts developed were deemed unsatisfactory in an evaluative process by potential end-users. This was on account of the designs having the wrong balance between open and private in those deemed spaces. While the view from planners was one of indifference to the proposals, Company 01, thought the proposals represented well their desires for economic performance of the project.

These observations, however, should be viewed in the full context of: (a) the collaboration and innovative approaches adopted by both companies including to crowdfunding the project implementation process and use of other technologies were a first for both companies in a joint project (b) Company 01 came to this project with a previously developed structure in terms of how it approaches relationships with stakeholders and information and knowledge sharing which at times was hierarchical (c) For Company 02, BIM was a recent adoption that was undergoing constant change in integrating it into the company's wider processes and capabilities. All these factors impacted on the FED processes in contributing to value in the project.

\section{OBSERVED KEY CONSTRAINTS TO FED VALUE CREATION}

Regarding FED processes in relation to the case study, it was possible to understand that most dimensions of the FED seen previously from the literature were applied. From the nine dimensions (see Figure 1), seven were applied or partially applied in the design process developed in the joint enterprise of Company 01 and Company 02.

However, there were a few notable observations: (i) the briefing process from Company 01 's perspective, appears heavily coupled with economic performance based on a business case as the over ridding benefit that Company 02 had to design the scope around. It is also correct to say that there was restricted information exchange between the stakeholders involved since it is notable that the briefing was presented in only one meeting of relatively short duration. (ii) An important limitation observed in this phase of the process related to information and knowledge sharing and requirements management, both of which differed in stated aims and observed practice. For example, many user requirements were adopted from workshop data which may have been superseded by new events. Regarding information and knowledge sharing, the roles of 
both companies meant that designers in company 02 relied on information from company 01, which did not always flow with swiftness and objectivity in representing user needs.

There also appears to be a predicated business ideology in the implementation of projects from company 01 's perspective. For example, the scope for the project was clear from the start of stakeholder engagement in Company 01 's view, such as predefined deliverables for each stakeholder at each time. From the perspective of Company 01, this was justified through (a) their entrenched and prior understanding of the city's housing market; and (b) their perceived flexibility in embracing modern practices in contributing to value co-creation.

Regarding project risk management, the researchers identified further opportunities to collaborate with wider construction teams during the earliest design phase to improve project risk performance as well as to receive feedback from end-users following commissioning in relation to risks. Table 2 represents a summary of the key identified influencing elements impacting on value at FED of the project.

Table 2: Summary of FED dimensions and the project

\begin{tabular}{|c|c|}
\hline FED Dimension & Current Project Applications \\
\hline The scope for the project & $\begin{array}{c}\text { Clear Project Scope delivered more quality and reliable } \\
\text { design. }\end{array}$ \\
\hline $\begin{array}{l}\text { Justification for the } \\
\text { Project }\end{array}$ & Something new, innovative following value understanding. \\
\hline High-level purpose & High quality of design and very integrated design delivery \\
\hline Outline Design & $\begin{array}{l}\text { Collaboration and trust were established before contracting } \\
\text { and maintained during the design process. }\end{array}$ \\
\hline Stakeholder Plan & $\begin{array}{l}\text { The main contractor sees the Design company as a partner } \\
\text { for continuing future project plans. }\end{array}$ \\
\hline Project Risk Management & $\begin{array}{c}\text { It was minimized by the previous knowledge from the end- } \\
\text { user's requirements (workshops). }\end{array}$ \\
\hline Outline Benefits/Costs & $\begin{array}{c}\text { Market visibility that aligns teams with possible current and } \\
\text { future opportunities. }\end{array}$ \\
\hline
\end{tabular}

Finally, the researchers identified value generation through each of the dimensions based on the relationship of the main actors in the project. Regarding the end-users, it cannot be definitively concluded that the partnership between the Companies generates real value. However, the companies delivered a different approach for design process and can use this opportunity to increase value generation for end-users in future.

\section{CONCLUSION}

This paper sought to explore the role of FED in value delivery of projects using a housing case study. The key identified influencing factors are a collaborative environment and trust. Both factors facilitate seamless information and knowledge sharing. The relationship between the two companies was important in defining the level of the information and knowledge flow and exchanges, From the nine FED dimensions, seven had a strong influencing relationship in the design process. Some key observations regarding the project processes in FED are essential to highlight.

Firstly, that there were missed opportunities in the processes particularly relating to the extensive data collated by Company 02, through their crowdfunding venture, that 
included a vast swath of user requirements in housing as part of their registration and membership with the company. Secondly, it appears that no objective effort was made to understand and integrate such up to date and extensive end-user data in developing the value proposition for the project. Such information and knowledge would potentially have played a vital role in further value generation, contribute to better communication, and support improved integrated designs. Those features were desired by end-users in their feedback as part of a participatory and co-creative environment.

Nonetheless, it is observed that there is a progressive development of trust among key stakeholders. This has indeed led to a new joint delivery as part of the wider scheme. At the same time, along the process, new opportunities have been explored, such as new knowledge that harnesses the role that stakeholders such as Company 02 bring to the value generation process. The hierarchical structure is now replaced with a network structure so that information and knowledge flow are in all directions from all stakeholders. The shared values have ensured that companies can achieve mutual benefits in the future, including shared market visibility and exploration of new innovative technologies. As part of a renewed effort and learning process, both companies now accept in future proposals that project value will be hinged on new workshop mechanisms to reflect current realities in collaboration with designers, other stakeholders and potential users.

In another approach, Company 01 is analyzing the funding perspective. This, however, has to be balanced against Company 01 's beliefs that shared spaces as part of housing are integral to the long-term investment decisions by end-users.

The researchers conclude that even with a less structured approach, FED played an important role in shaping design decision making and influencing value generation. The interviews and documents analysis enabled the researchers to identify the focus areas and correlations between stated and observed processes and with the end-user. It was observed that the focus of the relationships was between the two companies, and understanding their entrenched roles was notable, particularly for Company 02. Even if the design process was better structured, and the communication between designers and Company 01 was stronger, a strong relationship and trust established among the companies and between Company 02 and the end-user at the start were critical.

It is, therefore, argued that FED's role as one of the essential stages of the design process for facilitating the definition of the project purposes and goals; requirements capture, refinement and management; trade-offs made considering each consequence is still less well understood. The process of user requirements transformation into design requirements for the implementation by the professional teams is still less structured. Yet, the earliest opportunities and benefits for project collaboration to facilitate value generation and delivery seem to be understood.

FED decision making often affects later processes in the project lifecycle, as it is demonstrated in this paper. Early successes in FED can also be important in setting the tone for later processes. As such new research into FED, particularly in requirements management in establishing the intricate dynamics among them impacts value generation is still required. Future research can also extend the role and nature of stakeholder knowledge and information in influencing design decision making, particularly in dynamic contexts.

This paper identifies that these aspects can be crucial in reinforcing: (a) any defined or established trust and relationships among project stakeholders (b) enhanced benefits 
from any innovative initiatives adopted and (c) the collaborative role of the end-user particularly in early design phases.

Finally, researchers would like to thank Company 01 and Company 02 for the opportunity and interest in taking part in this research.

\section{REFERENCES}

Adeleke, A.Q., Bahaudin, A.Y., Kamaruddeen, A.M., Bamgbade, J.A., Salimon, M.G., Khan, M.W.A., and Sorooshian, S. 2017. "The Influence of Organizational External Factors on Construction Risk Management among Nigerian Construction Companies." Safety and Health at Work, 9(1) 115-124.

Almqvist, F. 2017. "The fuzzy front-end and the forgotten back-end: User involvement in later development phases." The Design Journal, 20, 2524-2533.

Azhar, S. 2011. "Building information modeling (BIM): Trends, benefits, risks, and challenges for the AEC industry." Leadership and Management in Engineering, 11(3), 241-252.

Baccarini, D. 1996. "The concept of project complexity-a review." J Int. Project Management, 14(4), 201-204.

Dainty, A., Leiringer, R., Fernie, S., and Harty, C. 2017. "BIM and the small construction firm: a critical perspective." Building Research and Information, 45(6), 696-709.

Fürstenberg, D., and Lædre, O. 2019. "Application of BIM Design Manuals: A Case Study." Proc. 27th Ann. Conf. Int. Group for Lean Construction, Pasquire, C. and Hamzeh, F.R. (eds.), Dublin, Ireland, pp. 145-156, doi.org/10.24928/2019/0147.

Giménez, Z., Mourgues, C., Alarcón, L.F., Mesa, H. 2019. "Proposal of a Model for Measuring Value in the Design Process." Proc. $27^{\text {th }}$ Ann. Conf. Int. Group for Lean Construction, Pasquire, C. and Hamzeh, F.R. (eds.), Dublin, Ireland, pp. 49-62, doi.org/10.24928/2019/0196.

Gomes, D., Tzortzopoulos, P., and Kagioglou, M. 2016. "Collaboration Through Shared Understanding in Early Design Stage." Proc. $2^{\text {th }}$ Ann. Conf. of the Int'l. Group for Lean Construction, Boston, MA, USA, sect.7 pp. 63-72.

Kagioglou, M., and Tzortzopoulos, P. 2016. "Benefits Realisation: An Investigation of Structure and Agency" Proc. 24 ${ }^{\text {th }}$ Ann. Conf. Int. Group for Lean Construction, Boston, MA, USA, sect. 4 pp. 183-192.

Koskela, L. 1992. Application of the New Production Philosophy to Construction. Technical Report \# 72. Center for Integrated Facility Engineering. Department of Civil Engineering. Stanford University, $75 \mathrm{pp}$.

Lawson, B. 2005. How Designers Think: The Design Process Demystified. Routledge, London, UK.

Mota, B., Biotto, C., Choudhury, A., Abley, S., Kagioglou, M. 2019. "Lean design management in a major infrastructure project in UK." Proc. $27^{\text {th }}$ Ann. Conf. Int. Group for Lean Construction, Pasquire, C. and Hamzeh, F.R. (eds.), Dublin, Ireland, pp. 3748, doi.org/10.24928/2019/0251.

Pikas, E., Koskela, L., Oehmen, J., and Dave, B. 2019. "From Checklists to Design Process Support Systems: Initial Framing." Proc. $27^{\text {th }}$ Ann. Conf. Int. Group for Lean Construction, Pasquire, C. and Hamzeh, F.R. (eds.), Dublin, Ireland, pp. 83-96, doi.org/10.24928/2019/0173.

Polat, G., and Ballard, G. "Waste in Turkish construction: need for lean construction techniques." Proc. 12 $2^{\text {th }}$ Ann. Conf. Int. Group for Lean Construction, August, Denmark, 4 pp. 88-501. 
Sacks, R., Dave, B.A., Koskela, L. and Owen, R. 2009. "Analysis Framework for the Interaction Between Lean Construction and Building Information Modelling." In: Cuperus, Y. and Hirota, E. H. (eds.), Proc. $17^{\text {th }}$ Ann. Conf. Int. Group for Lean Construction, Taipei, Taiwan, 15-17 July, pp. 221-234.

Salam, M., Forsythe, P., and Killen, C. 2019. "Exploring Interdisciplinary Collaboration in the Detailed Design Phase of Construction Projects." Proc. 27th Ann. Conf. Int. Group for Lean Construction, Pasquire, C. and Hamzeh, F.R. (eds.), Dublin, Ireland, pp. 761-772, doi.org/10.24928/2019/0149.

Samset, K., and Volden, G.H. 2016. "Front-end definition of projects: Ten paradoxes and some reflections regarding project management and project governance." Int. J. Project Management, 34(2), 297-313.

San Cristóbal, J. R. 2017. "Complexity in Project Management." Procedia Computer Science, 121, 762-766.

Serugga, J., Kagioglou, M., and Tzortzopoulos, P. 2019. “A Predictive Method for Benefits Realisation Through Modelling Uncertanty in Front End Design." Proc. $27^{\text {th }}$ Ann. Conf. Int. Group for Lean Construction, Pasquire, C. and Hamzeh, F.R. (eds.), Dublin, Ireland, pp. 1321-1332, doi.org/10.24928/2019/0161.

Serugga, J., Kagioglou, M., and Tzortzopoulos, P. 2020. "Front End Projects Benefits Realisation from a Requirements Management Perspective-A Systematic Literature Review." Buildings, 10(5), 83.

Smyth, H., Lecoeuvre, L., and Vaesken, P. 2018. "Co-creation of value and the project context: Towards application on the case of Hinkley Point C Nuclear Power Station." Int. J. Project Management, 36(1), 170-183.

Tezel, A., Koskela, L., and Aziz, Z. 2018. "Current condition and future directions for lean construction in highways projects: A small and medium-sized enterprises (SMEs) perspective." Int. J. Project Management, 36(2), 267-286.

Turner, J. R., and Cochrane, R. A. 1993. "Goals-and-methods matrix: coping with projects with ill defined goals and/or methods of achieving them." Int. J. Project Management, 11(2), 93-102.

Von Heyl, J. and Demir, S.-T. 2019. "Digitizing Lean Construction with Building Information Modeling." Proc. 27th Ann. Conf. Int. Group for Lean Construction, Pasquire, C. and Hamzeh, F.R. (eds.), Dublin, Ireland, pp. 843-852, doi.org/10.24928/2019/0122.

Whelton, M. \& Ballard, G. 2002. "Project Definition and Wicked Problems." In: Formoso, C.T. and Ballard, G. (eds.), Proc. 10 ${ }^{\text {th }}$ Ann. Conf. Int. Group for Lean Construction, Gramado, Brazil, 6-8 Aug., pp. 375-387

Williams, T.M. 1999. “The need for new paradigms for complex projects." Int. J. Project Management, 17(5), 269-273. 